Tropical Journal of Pharmaceutical Research June 2019; 18 (6): 1191-1196

ISSN: $1596-5996$ (print); 1596-9827 (electronic)

(C) Pharmacotherapy Group, Faculty of Pharmacy, University of Benin, Benin City, 300001 Nigeria.

\title{
Notoginsenoside R1 improves monocrotaline-induced pulmonary arterial hypertension via modulation NF-KB signaling in rats
}

\author{
Yinglu Feng, $\mathrm{Na} \mathrm{Hu,} \mathrm{Min} \mathrm{Tang,} \mathrm{Shanglong} \mathrm{Yao*}$ \\ Department of Anesthesiology, Union Hospital, Tongji Medical College, Huazhong University of Science and Technology, \\ Wuhan 430022, China
}

*For correspondence: Email: yaoshanglongklk@163.com; Tel: 0086-27-85351653

Sent for review: 17 February 2019

Revised accepted: 28 May 2019

\begin{abstract}
Purpose: To investigate the potentials of notoginsenoside R1 (NGR1) in ameliorating inflammation and pulmonary vascular remodeling in rats with pulmonary arterial hypertension (PAH) induced by monocrotaline (MCT), and to examine the mechanisms underlying such effects.

Methods: Eight-week-old male Sprague Dawley rats were randomly divided into groups: control, MCT, $M C T+5 \mathrm{mg} / \mathrm{kg}$ NGR1, MCT+12.5mg/kg NGR1, and MCT + $25 \mathrm{mg} / \mathrm{kg} \mathrm{NGR1.} \mathrm{Right} \mathrm{cardiac}$ catheterization was used to measure pulmonary hemodynamics. Pulmonary morphology was evaluated with the aid of $H$ \& E staining. Serum levels of inflammatory cytokines were measured using ELISA, while levels of inflammation-associated factors in the lung were measured using RT-PCR. NF-KB (nuclear factor kappa-light-chain-enhancer of activated B cells) and IKBa (nuclear factor of kappa light polypeptide gene enhancer in B cells inhibitor, alpha) protein levels were determined by western blot. Results: Pulmonary hemodynamics and pulmonary morphology worsened following MCT injection and were accompanied by NF-KB pathway activation and elevated levels of inflammation-associated factors. In contrast, MCT treatment followed by NGR1 treatment ameliorated MCT-induced PAH by improving pulmonary hemodynamics and pulmonary vascular remodeling while reducing $N F-K B$ activation and levels of inflammation-associated factors.

Conclusion: NGR1 exerts ameliorative effects on MCT-induced PAH by inhibiting NF-KB pathway. Therefore, NGR1 may be a new potential therapy for PAH.
\end{abstract}

Keywords: Notoginsenoside R1, Monocrotaline-induced pulmonary arterial hypertension, Vascular inflammation, NF-KB pathway

This is an Open Access article that uses a fund-ing model which does not charge readers or their institutions for access and distributed under the terms of the Creative Commons Attribution License (http://creativecommons.org/licenses/by/4.0) and the Budapest Open Access Initiative (http://www.budapestopenaccessinitiative.org/read), which permit unrestricted use, distribution, and reproduction in any medium, provided the original work is properly credited.

Tropical Journal of Pharmaceutical Research is indexed by Science Citation Index (SciSearch), Scopus, International Pharmaceutical Abstract, Chemical Abstracts, Embase, Index Copernicus, EBSCO, African Index Medicus, JournalSeek, Journal Citation Reports/Science Edition, Directory of Open Access Journals (DOAJ), African Journal Online, Bioline International, Open-J-Gate and Pharmacy Abstracts

\section{INTRODUCTION}

Pulmonary arterial hypertension (PAH), a multifactorial and life-threatening illness, presents as a persistent increase in pulmonary artery pressure and ultimately results in right ventricular failure and death [1]. The pathogenesis of PAH includes pulmonary vasoconstriction, thrombosis, inflammation, and oxidative stress [2-4]. Accumulating evidence reveal pulmonary vascular inflammation has an essential role in PAH [3,5]. Inflammatory 
responses promote abnormal contraction of pulmonary vessels and proliferation of pulmonary arterial smooth muscle cells (PASMCs), resulting in pulmonary arterial remodeling and pulmonary hypertension $[6,7]$.

Nuclear factor-kappa B (NF-kB) is closely associated with inflammation and cell proliferation [8]. Nuclear Factor-kB increases the expression of tumor necrosis factor (TNF- $\alpha$ ), intercellular adhesion molecule-1 (ICAM-1), and monocyte chemoattractant protein-1 (MCP-1), all of which are involved in the development of pulmonary hypertension $[9,10]$. Nuclear Factor$\mathrm{KB}$ activation is also a pathological characteristic of PASMC in patients with idiopathic $\mathrm{PAH}$, and inhibition of NF-kB activity is an effective therapy for $\mathrm{PAH}[11-13]$.

Classically, $\mathrm{PAH}$ is treated with calcium channel blockers, but current therapeutic strategies are focused on targets such as phosphodiesterase type 5 inhibitors, endothelin receptor antagonists, and prostanoids [14]. Although these medications provide clinical benefits, $\mathrm{PAH}$ patients continue to suffer from poor prognoses and low survival rates [15]. Therefore, it is urgent to develop novel therapeutic strategies for $\mathrm{PAH}$ treatment. Panax notoginseng saponins (PNS) are the major active ingredients derived from Panax notoginseng, widely used in traditional Chinese medicine to stanch bleeding [16]. Notoginsenoside R1 (NGR1) is a PNS with antiinflammatory, cardioprotective, and anti-oxidative properties [17-19]. It alleviates inflammatory responses in human epithelial cells and inhibits vascular smooth muscle cell proliferation $[17,20]$. Therefore, the present study was designed to investigate whether NGR1 had a therapeutic effect on MCT-induced $\mathrm{PAH}$ in rats and to discover the mechanisms underlying any such effects.

\section{EXPERIMENTAL}

\section{Establishment of PAH model}

Eight-week-old male Sprague-Dawley rats were acquired from Shanghai SLAC Laboratory Animal Co., Ltd. All rats were maintained under standard conditions with constant temperature $\left(22 \pm 2{ }^{\circ} \mathrm{C}\right)$, constant humidity $(60 \pm 5 \%)$, and a $12 \mathrm{~h}$ light/dark cycle. All animal experiments were carried out in accordance with the guidelines of International Ethical Guidelines for Biomedical Research [21], and were approved by the Ethics Committee of Huazhong University of Science and Technology (no. EC2017HU0048).
Rats were randomly divided into five treatment groups ( $\mathrm{n}=8$ per group): control, MCT, MCT + 5 $\mathrm{mg} / \mathrm{kg} \mathrm{NGR1}$, MCT + $12.5 \mathrm{mg} / \mathrm{kg} \mathrm{NGR1}$ and $\mathrm{MCT}+25 \mathrm{mg} / \mathrm{kg}$ NGR1. A single dose of MCT (50 mg/kg; Sigma-Aldrich) was injected intraperitoneally (IP) to induce experimental $\mathrm{PAH}$. Sham-treated animals were injected with an equivalent volume of saline. Subsequently, rats in the MCT + NGR1 groups were administered with NGR1 (Shanghai Tauto Biotech Co., Ltd.) by oral gavage daily for 21 days. Rats in control group and MCT-only treated control group were administered with equal volume of normal saline.

\section{Hemodynamic measurements}

Rats were anesthetized with $10 \%$ chloral hydrate (IP injection; $3 \mathrm{ml} / \mathrm{kg}$; Sigma-Aldrich) 21 days after MCT injection. A polyethylene catheter equipped with a pressure sensor was inserted into the jugular vein and directed through the right atrium and right ventricle into the pulmonary artery. Various parameters for assessing pulmonary artery pressure were then recorded. Finally, heart tissues of rats were excised and dissected into three parts: left ventricle (LV), interventricular septum (S), and right ventricle (RV). Right ventricular hypertrophy index (RVHI) was assessed as as in Eq 1.

$\mathrm{RVHI}=$ weight $_{\mathrm{RV}} /\left(\right.$ weight $_{\mathrm{LV}}+$ weight $\left._{\mathrm{S}}\right) \ldots \ldots$ (1)

\section{Hematoxylin and eosin (H \& E) staining}

The right lower lung lobe was harvested and fixed in $4 \%$ paraformaldehyde (Sigma-Aldrich). The lung was embedded in paraffin and sectioned into tissue slices $(5 \mu \mathrm{m})$. H \& $E$ staining was carried out at room temperature with hematoxylin $(0.5 \%$; ZSGB-BIO) staining for $3 \mathrm{~min}$, followed by eosin (0.5\%; ZSGB-BIO) staining for 2 min. Subsequently, the tissue slices were dehydrated and sealed. Finally, a light microscope (Olympus) was used to observe and photograph the $\mathrm{H}$ \& E-stained slides.

\section{Evaluation of serum cytokines}

Rat plasma was harvested by retro-orbital injection, and the serum was separated by centrifugation $(6000 \mathrm{rpm}, 10 \mathrm{~min})$ before collection. Levels of serum cytokines IL-6 and TNFa were measured by ELISA ( $R$ \& $D$ systems).

\section{Determination of tissue RNA}

RNA was isolated from exercised rat lung tissues which were homogenized in TRIzol reagent 
(Invitrogen) with Tissuelyser-192 (Shanghai JingXin). Message RNA (mRNA) was further purified using RNeasy Plus Micro and Mini Kits (QIAGEN). Complementary DNA (cDNA) was synthesized using the PrimeScript ${ }^{\mathrm{TM}} \mathrm{RT}$ Reagent Kit (Takara), and quantitative RT-PCR was performed on an ABI 7900 instrument (Applied Biosystems). The primer sequences used to amplify Icam1 (intercellular adhesion molecule 1), Hmgb1 (high mobility group box 1), and Actb (actin) are listed in Table 1.

\section{Western blotting}

Harvested rat lung tissues were homogenized in sterile physiological saline and total protein extracts were prepared using RIPA lysis buffer (Beyotime). Protein concentrations were determined using the BCA Protein Assay Kit (Thermo Fisher Scientific). Equivalent amounts of protein were loaded into each lane of a $10 \%$ polyacrylamide gel containing sodium dodecyl sulfate (SDS). Proteins were separated by electrophoresis and transferred to PVDF membranes (Millipore). Membranes were blocked in $5 \%$ skim milk at room temperature for $2 \mathrm{~h}$ before adding primary antibodies against IKBa (Abcam), NF-KB p65 (Abcam) and $\beta$-actin (Abcam).

The membranes and antibodies were incubated at $4^{\circ} \mathrm{C}$ overnight. Membranes were washed three times in Tris-buffered saline containing $0.1 \%$ Tween 20 before incubating with HRPconjugated secondary antibodies (Abcam) for 1 h. Proteins were visualized with SuperSignal West Dura Extended Duration Substrate (Thermo Fisher Scientific) and analyzed using an ImageQuant LAS 4000 Mini (GE Healthcare Life Sciences).

\section{Statistical analysis}

Data were derived from three independent experiments and presented as the mean \pm SEM. One-way analysis of variance (ANOVA) was used to evaluate the statistical differences among groups and $p<0.05$ was considered statistical significant. SPSS and Prism softwares were used for data analyses.

Table 1: Primer sequences for Icam1, Hmgb1 and Actin

\section{RESULTS}

\section{NGR1 improved pulmonary hemodynamics in rats with MCT-induced PAH}

To determine whether notoginsenoside RI (NGR1) might be an effective treatment for pulmonary arterial hypertension (PAH), this study used monocrotaline (MCT) to induce $\mathrm{PAH}$ in Sprague-Dawley rats. After an initial treatment with MCT $(50 \mathrm{mg} / \mathrm{kg})$, rats were treated with NGR1 (at concentrations of $0,5,12.5$, or 25 $\mathrm{mg} / \mathrm{kg}$ ), once a day, for 21 days and then assessed. Hemodynamic parameters, including right ventricular systolic pressure (RVSP), mean pulmonary arterial pressure (mPAP), pulmonary arterial systolic pressure (PASP) and right ventricular hypertrophy index (RVHI), were significantly increased in the MCT-treated group (Figure 1). Notoginsenoside R1 (NGR-1)treatment restored normal hemodynamic parameters in MCT-treated rats in a dosedependent manner. Importantly, in the MCT + 25 $\mathrm{mg} / \mathrm{kg}$ NGR1 group, the levels of RVSP, mPAP, PASP, and RVHI were similar to their levels in the sham-treated control group (Figure 1). These results indicate that NGR1 may protect rats from MCT-induced PAH.
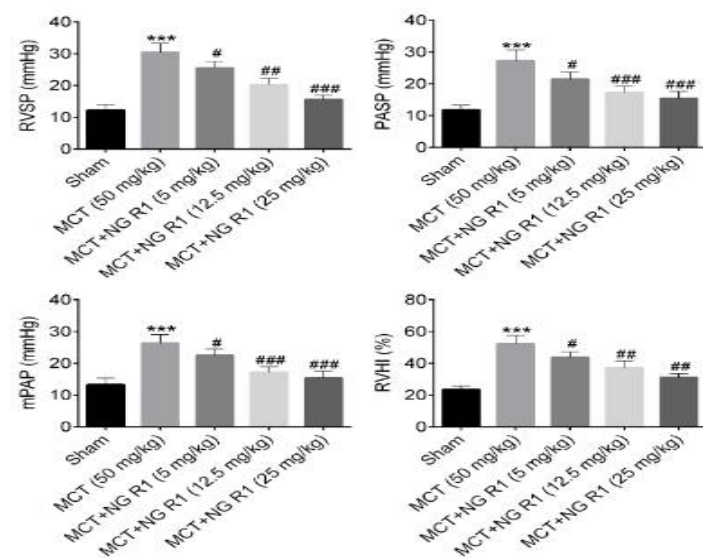

Figure 1: Effect of NGR1 treatment on pulmonay hemodynamics in MCT-induced PAH. RVSP, PASP, mPAP and RVHI were measured for each group 21 days after initial treatment with MCT $(n=8) .{ }^{* \star *} p<$ 0.001 vs. sham group. $\# p<0.05$, \#\# $p<0.01$, \#\#\# $p<$ 0.001 vs. MCT group

\begin{tabular}{|c|c|c|}
\hline Gene & Upstream primer & Downstream primer \\
\hline Icam1 & 5'-TTCCTTCTCTATTACCCC-3' & 5'-GTGAGCGTCCATATTTAG-3' \\
\hline$H m g b 1$ & 5'-GAGATCCTAAGAAGCCGAGA-3' & 5'-СТTССТСАТССТСТTСАТСС-3' \\
\hline Actin & 5'-ATTTGGCACCACACTTTCTACAATGAGCTGCG- & \\
\hline & $3^{\prime}$ & $\begin{array}{l}\text { GCAGATGTGGATCAGCAAGCAGGAGTAC } \\
\text { GATG-3' }\end{array}$ \\
\hline
\end{tabular}




\section{Effect of NGR1 on MCT-induced pulmonary morphological changes}

To assess whether NGR1 might protect against MCT-induced pulmonary artery remodeling, $\mathrm{H} \& \mathrm{E}$ staining of lung tissue sections was performed. Compared with the sham-treated group, the pulmonary arteries of the MCT-treated group had thicker walls and narrower lumens (Figure 2). In addition, immune cell infiltration was evident, indicating the presence of pulmonary interstitial inflammation (Figure 2). In contrast, NGR1 treatment led to a more normal pulmonary vascular wall structure and less inflammatory infiltration, again in a dose-dependent manner. Strikingly, very little pulmonary artery remodeling was detected in the MCT + $25 \mathrm{mg} / \mathrm{kg}$ NGR1 group (Figure 2). These results suggest that NGR1 ameliorates MCT-induced pulmonary arterial remodeling.

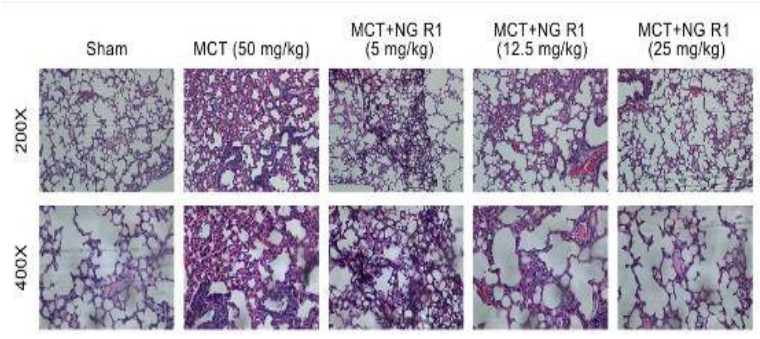

Figure 2: Protective effects of NGR1 on pulmonary morphological changes induced by MCT. $H$ \& $E$ staining of rat lung tissues in different groups $(n=6$ 8)

\section{NGR1 inhibited MCT-induced pulmonary vascular inflammation}

To investigate the mechanisms underlying the influence of NGR1 on MCT-induced PAH, serum protein levels of the proinflammatory cytokines tumor necrosis factor-alpha (TNF- $\alpha$ ) and interleukin-6 (IL-6) were determined. Tumor Necrosis Factor- $\alpha$ and IL- 6 levels significantly ( $p$ $<0.001$ )increased in rats treated with MCT alone, but when MCT treatment was followed by NGR1 treatment, a dose-dependent reductions in IL-6 and TNF- $\alpha$ levels was observed (Figure 3 A). Similarly, Icam1 (intracellular adhesion molecule 1) and Hmgb1 (high mobility group box 1) expressions were elevated in lung tissue from the MCT-treated group when compared to the sham-treated group, but MCT treatment followed by NGR1 treatment restored normal expression levels (Figure $3 \mathrm{~B}$ ). These results suggest that NGR1 reduces pulmonary inflammatory response in rats with MCT-induced PAH.
NF-kB signaling pathway mediates the protective effects of NGR1 in MCT-induced PAH rats

The inflammatory response depends, in part, on the activation of NF-KB and the degradation of IKBa. Therefore, to investigate how NGR1 might inhibit the expression of pro-inflammatory factors like TNF- $\alpha$ and IL-6, NF-KB and IKBa protein levels were determined by western blot analysis. Compared to the sham-treated group, rats treated with MCT had significantly $(p<0.001)$ increased NF-KB levels and decreased IKBa levels (Figure $3 \mathrm{C}$ ). Conversely, in the MCT + NGR1 groups, NF-kB levels decreased, whereas IKBa levels increased significantly $(p<0.001)$ (Figure $3 \mathrm{C}$ ). These results demonstrate that the NF-KB signaling pathway is crucial for the protective effects of NGR1.

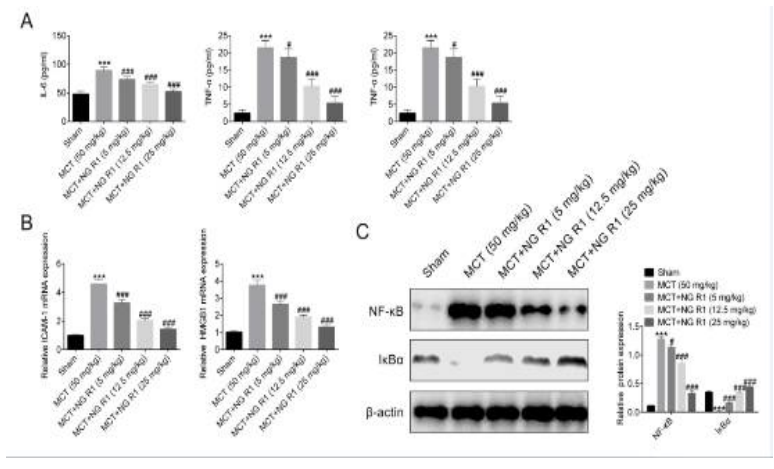

Figure 3: Effect of NGR1 treatment on the expressions of MCT-induced markers in pulmonary vascular inflammation. (A) Levels of IL-6 and TNFa in rat serum determined by ELISA. (B) Expressions of Icam1 and Hmgb1 in rat lung tissue determined by qRT-PCR. (C) Protein levels of NF-kB and IKBa in rat lung tissue. ${ }^{* \star *} p<0.001$ vs. sham group. $\# p<0.05$, $\# \# \#<0.001$ vs. MCT group

\section{DISCUSSION}

In the current study, rats with MCT-induced PAH exhibited increases in pulmonary hemodynamics, pathological changes in pulmonary structure, and pulmonary vascular inflammation. In rats treated with MCT followed by treatment with NGR1 for 21 days, these monocrotaline-induced effects were attenuated. Mechanistically, the protective effect of NGR1 on MCT-induced PAH depends on the suppression of NF-KB signaling pathway. MCT, a two-pyrrole alkaloid, is transformed into MCT pyrrole (MCTP) in the liver by P450 monooxygenase [22]. MCT pyrrole is harmful to pulmonary arterial endothelial cells leading to vascular injury, remodeling, and inflammation [22]. The pathological symptoms induced by MCT in rats are comparable to the symptoms of human $\mathrm{PAH}$, making the MCT-induced PAH rat model suitable for PAH studies [22]. In the 
present study, MCT treatment significantly increased RVSP, PASP, MPAP, and RVHI; thickened the pulmonary artery wall and narrowed its lumen; and enhanced inflammatory infiltration, thus validating the MCT-induced $\mathrm{PAH}$ rat model. These MCT-induced effects were alleviated by NGR1 administration.

High levels of the pro-inflammatory cytokines TNF- $\alpha$ and IL- 6 might induce pulmonary artery endothelial cell damage and abnormal PASMC proliferation, and contribute to PAH $[3,7]$. ICAM1 , an intercellular adhesion molecule present in endothelial cells, facilitates leukocyte endothelial transmigration [23]. High Mobility Group Box-1 Protein, produced by activated immune cells, acts as a cytokine mediator of inflammation [24]. Therefore, ICAM-1 and HMGB1 can be regarded as biomarkers of inflammation. In this study, NGR1 reduced the elevated levels of IL-6, TNF$\alpha$, ICAM-1 and HMGB1 induced by MCT, thereby demonstrating that NGR1 has possible antiinflammatory effects.

NF-kB, a major transcription factor, regulates many genes involved in both the innate and adaptive immune responses [25]. Normally, dimers of NF-KB bind to inhibitory IKB proteins in the cytoplasm. Upon stimulation, IKB kinase phosphorylates the IKBs, thereby targeting them for degradation and freeing NF-KB to translocate into the nucleus to induce inflammatory cascades [26]. In the current study, the MCT-induced increase in NF-KB protein levels and decrease in IKB $\alpha$ levels were inhibited by NGR1. These findings indicate that suppression of the NF-KB signaling pathway contributes to the molecular mechanism underlying the anti-inflammatory effects of NGR1.

\section{CONCLUSION}

The findings of the present study demonstrate that NGR1 exerts effects that counter MCTinduced $\mathrm{PAH}$, and these effects are associated with NF-KB pathway. Thus, NRG1 is a potential novel therapy for $\mathrm{PAH}$.

\section{DECLARATIONS}

\section{Conflict of interest}

No conflict of interest is associated with this work.

\section{Contribution of authors}

We declare that this work was done by the authors named in this article and all liabilities pertaining to claims relating to the content of this article will be borne by the authors. Shanglong Yao and $J$ Yinglu Feng designed all the experiments and revised the manuscript. $\mathrm{Na} \mathrm{Hu}$ and Min Tang performed the experiment.

\section{Open Access}

This is an Open Access article that uses a funding model which does not charge readers or their institutions for access and distributed under the terms of the Creative Commons Attribution License (http://creativecommons.org/licenses/by/ 4.0) and the Budapest Open Access Initiative (http://www.budapestopenaccessinitiative.org/rea d), which permit unrestricted use, distribution, and reproduction in any medium, provided the original work is properly credited.

\section{REFERENCES}

1. Lai YC, Potoka KC, Champion HC, Mora AL, Gladwin MT. Pulmonary arterial hypertension: the clinical syndrome. Circ Res 2014; 115(1): 115-130.

2. Chaumais MC, Ranchoux B, Montani D, Dorfmuller $P, T u$ $L$, Lecerf F, Raymond N, Guignabert C, Price L, Simonneau $G$ et al. $N$-acetylcysteine improves established monocrotaline-induced pulmonary hypertension in rats. Respir Res 2014; 15: 65-71.

3. Rabinovitch $M$, Guignabert $C$, Humbert M, Nicolls MR. Inflammation and immunity in the pathogenesis of pulmonary arterial hypertension. Circ Res 2014; 115(1): 165-175.

4. Ahmed LA, Obaid AA, Zaki HF, Agha AM. Role of oxidative stress, inflammation, nitric oxide and transforming growth factor-beta in the protective effect of diosgenin in monocrotaline-induced pulmonary hypertension in rats. Eur J Pharmacol 2014; 740: 379387.

5. Sutendra $G$, Dromparis $P$, Bonnet $S$, Haromy $A$, McMurtry MS, Bleackley RC, Michelakis ED. Pyruvate dehydrogenase inhibition by the inflammatory cytokine TNF-alpha contributes to the pathogenesis of pulmonary arterial hypertension. J Mol Med (Berl) 2011; 89(8): 771783.

6. Le HM, Tu L, Ricard N, Phan C, Thuillet R, Fadel E, Dorfmüller $P$, Montani $D$, De MF, Humbert $M$. Proinflammatory Signature of the Dysfunctional Endothelium in Pulmonary Hypertension. Role of the Macrophage Migration Inhibitory Factor/CD74 Complex. Am J Respir Cri Care Med 2015; 192(8): 983-988.

7. Hassoun PM, Mouthon L, Barbera JA, Eddahibi S, Flores SC, Grimminger F, Jones PL, Maitland ML, Michelakis $E D$, Morrell NW et al. Inflammation, growth factors, and pulmonary vascular remodeling. J Am Coll Cardiol 2009; 54(1 Suppl): S10-19.

8. Zhang $Y$, Huang $O$, Zhang $W$, Liu L, Xu C. Astragaloside $I V$ exerts anti-inflammatory role in endometriosis by 
downregulating TLR4/NF-KB pathway. Trop J Pharma Res 2019; 18(3): 539-545.

9. Kimura $H$, Okada O, Tanabe N, Tanaka Y, Terai $M$, Takiguchi $Y$, Masuda M, Nakajima N, Hiroshima $K$, Inadera $H$ et al. Plasma monocyte chemoattractant protein-1 and pulmonary vascular resistance in chronic thromboembolic pulmonary hypertension. Am J Respir Crit Care Med 2001; 164(2): 319-324.

10. Huang $W$, Huang $M$, Ouyang $H$, Peng J, Liang J. Oridonin inhibits vascular inflammation by blocking NFkappaB and MAPK activation. Eur J Pharmacol 2018; 826: 133-139.

11. Hosokawa S, Haraguchi G, Sasaki A, Arai H, Muto S, Itai A, Doi S, Mizutani S, Isobe M. Pathophysiological roles of nuclear factor kappaB (NF-kB) in pulmonary arterial hypertension: effects of synthetic selective NF-kB inhibitor IMD-0354. Cardiovasc Res 2013; 99(1): 35-43.

12. Li L, Wei C, Kim IK, Janssen-Heininger $Y$, Gupta S. Inhibition of nuclear factor-kappaB in the lungs prevents monocrotaline-induced pulmonary hypertension in mice. Hypertension 2014; 63(6): 1260-1269.

13. Sawada H, Mitani $Y$, Maruyama J, Jiang BH, Ikeyama $Y$, Dida FA, Yamamoto $H$, Imanaka-Yoshida $K$, Shimpo $H$, Mizoguchi $A$ et al. A nuclear factor-kappaB inhibitor pyrrolidine dithiocarbamate ameliorates pulmonary hypertension in rats. Chest 2007; 132(4): 1265-1274.

14. Galie N, Humbert M, Vachiery JL, Gibbs S, Lang I, Torbicki A, Simonneau G, Peacock A, Vonk Noordegraaf A, Beghetti $M$ et al. [2015 ESC/ERS Guidelines for the diagnosis and treatment of pulmonary hypertension]. Kardiol Pol 2015; 73(12): 1127-1206.

15. Benza RL, Miller DP, Barst RJ, Badesch DB, Frost $A E$, McGoon MD. An evaluation of long-term survival from time of diagnosis in pulmonary arterial hypertension from the REVEAL Registry. Chest 2012; 142(2): 448456.

16. Yang $X$, Xiong $X$, Wang $H$, Wang J. Protective effects of panax notoginseng saponins on cardiovascular diseases: a comprehensive overview of experimental studies. Evid Based Complement Alternat Med 2014; 2014: 204-209.
17. Su P, Du S, Li H, Li Z, Xin W, Zhang W. Notoginsenoside $R 1$ inhibits oxidized low-density lipoprotein induced inflammatory cytokines production in human endothelial EA.hy926 cells. Eur J Pharmacol 2016; 770: 9-15.

18. Zhang HS, Wang SQ. Notoginsenoside R1 inhibits TNFalpha-induced fibronectin production in smooth muscle cells via the ROS/ERK pathway. Free Radic Biol Med 2006; 40(9): 1664-1674.

19. Yu $Y$, Sun $G$, Luo $Y$, Wang $M$, Chen R, Zhang J, Ai $Q$, Xing $N$, Sun $X$. Cardioprotective effects of Notoginsenoside $R 1$ against ischemia/reperfusion injuries by regulating oxidative stress- and endoplasmic reticulum stress- related signaling pathways. Sci Rep 2016; 6: 217-230.

20. Fang $H$, Yang $S$, Luo $Y$, Zhang $C$, Rao $Y$, Liu R, Feng $Y$, $Y u$ J. Notoginsenoside R1 inhibits vascular smooth muscle cell proliferation, migration and neointimal hyperplasia through PI3K/Akt signaling. Sci Rep 2018; 8(1): 7595-7599.

21. International ethical guidelines for biomedical research involving human subjects. Bull Med Ethics 2002; 182: 17-23.

22. Nogueira-Ferreira $R$, Vitorino $R$, Ferreira $R$, HenriquesCoelho $T$. Exploring the monocrotaline animal model for the study of pulmonary arterial hypertension: A network approach. Pulm Pharmacol Ther 2015; 35: 8-16.

23. Yang $L$, Froio RM, Sciuto TE, Dvorak AM, Alon $R$, Luscinskas FW. ICAM-1 regulates neutrophil adhesion and transcellular migration of TNF-alpha-activated vascular endothelium under flow. Blood 2005; 106(2): 584-592.

24. Wang $H$, Bloom $O$, Zhang $M$, Vishnubhakat JM, Ombrellino $M$, Che J, Frazier $A$, Yang $H$, Ivanova $S$, Borovikova $L$ et al. HMG-1 as a late mediator of endotoxin lethality in mice. Science 1999; 285(5425): 248-251.

25. Smith EM, Gregg M, Hashemi F, Schott L, Hughes TK. Corticotropin Releasing Factor (CRF) activation of NFkappa B-directed transcription in leukocytes. Cell Mol Neurobiol 2006; 26(4-6): 1021-1036.

26. Jacobs MD, Harrison SC. Structure of an lkappa $B$ alpha/NF-kappa B complex. Cell 1998; 95(6): 749-758. 